\title{
High Circulating Sclerostin Level as Osteoporosis Risk Factor in Male Geriatric Population at Sanglah Hospital Bali
}

\author{
Sandra Suryarini ${ }^{1 *}$ D , RA. Tuty Kuswardhani ${ }^{1,2}$, I. Gusti Lanang Ngurah Agung Artha Wiguna ${ }^{3}$ \\ ${ }^{1}$ Internal Medicine Education Program, Faculty of Medicine, Udayana University, Bali, Indonesia; ${ }^{2}$ Department of Internal \\ Medicine, Geriatric Division, Sanglah General Hospital, Denpasar, Bali, Indonesia; ${ }^{3}$ Department of Orthopedic and Traumatology, \\ Spine Orthopedic Division, Sanglah General Hospital, Denpasar, Bali, Indonesia
}

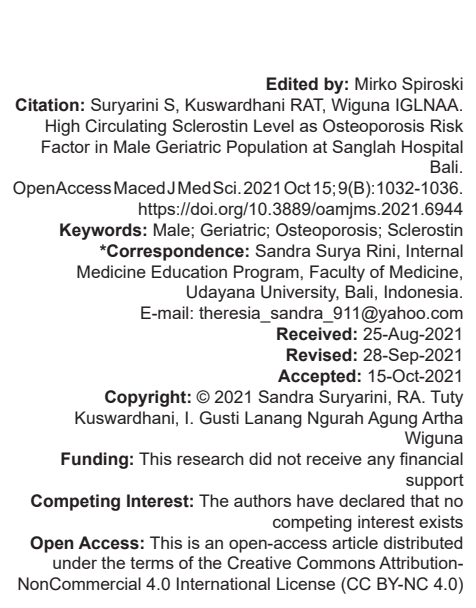

\section{Introduction}

Life expectancy has continuously increased all over the globe in the past few decades. As in 1950, data showed that life expectancy was only 46 years old, and then, it increased significantly in 2009 reaching 69 years old. Life expectancy was predicted to reach 75 years old by 2020 . The World Health Organization (WHO) stated that Indonesia's average life expectancy in 2017 was 67.1 years old for male and 71.2 years old for female [1]. The impact of increasing life expectancy in Indonesia and all over the world is that the number of elderly population has continuously increased overtime. Asia and Indonesia in particular have reached aging population since 2015 since the number of elderly population in Indonesia has reached more than $7 \%$. According to Indonesian Health Ministry, Indonesia has 22.1 million elderly population in 2017 and this number expected to increase 27.08 million (in 2020), 33.69 million (in 2025), 40.95 million (in 2030), and 48.19 million (in 2035).
The recent discoveries and advances in the molecular pathophysiology of osteoporosis have lead us to newly discovered Wnt/ $\beta$-catenin pathway which thought to involved in bone mass regulation. Activation of Wnt/ $\beta$-catenin pathway will increase proliferation and differentiation of osteoblast and decrease apoptosis of mature osteoblast. As a consequence, there will be new bone formation and increase bone density. Sclerostin, a glycoprotein secreted by osteocyte, is a potent inhibitor of osteoblast formation and differentiation and an antagonist of the $W n t / \beta$-catenin signaling pathway [2]. Sclerostin was discovered through various genetic researches, especially sclerosteosis and van Buchem disease. These two rare genetic disorders were associated with low or absence level of sclerostin and gene mutation at region 17q12-q21 and cause excessive growing of bone and bone strength [3]. This phenomenon leads to sclerostin role in bone formation regulation.

Although osteoporosis is more common in women than in men, most research shows that the condition going underdiagnosed and undertreated 
in male geriatric population. Moreover, there are still debates whether sclerostin plays a role in osteoporosis in several studies. Considering those facts, we would like to aim this paper to study further about association between sclerostin level and osteoporosis in male geriatric.

\section{Methods}

A matched case-control design in age and sex was implemented to address the objective of this study. Research was conducted in Sanglah General Hospital, Denpasar, Bali, starting from May 2019 until the number of samples needed was completely collected. Samples of study are all male geriatric patients aged equal or more than 60 years old visited geriatric polyclinic, orthopedic polyclinic, pulmonology polyclinic, or who undergoing treatment or currently hospitalized in Sanglah General Hospital who have not received any osteoporosis medications yet. Written informed consent was obtained from all subjects.

A total of 54 elderly subjects were recruited in this matched case-control study and divided into control group ( $n=27$ ) and osteoporosis group $(n=27)$. Subjects were excluded if they had a history of multiple myeloma, van Buchem disease, hyperparathyroidism, chronic kidney disease (CKD) Stage III, IV, and V with eGFR $<60 \mathrm{ml} / \mathrm{min} / 1.73 \mathrm{~m}^{2}$, lung tuberculosis, and lung cancer. Some variables such as age, history of diabetes mellitus (DM) type 2, physical activity, sun exposure, alcohol consumption, and bone mass index (BMI) were controlled by analysis. Bone mineral density (BMD) was measured by dual-energy X-ray absorptiometry using GE lunar prodigy bone densitometer. Serum sclerostin levels were measured using a recently available Quantikine $^{\circledR}$ ELISA Human SOST Immunoassay ( $R$ and D Systems) Cat. No: DSST00. This study was conducted with approval from Ethics Committee of Sanglah General Hospital, Denpasar, Bali.

Data were analyzed using IBM Statistical Package for the Social Sciences (SPSS) version 25 software. Descriptive analysis was calculated to determine baseline characteristics of all subjects such as age, body weight, height, BMI, educational status, smoking status, smoking intensity, alcohol consumption, sun exposure, physical activity level, and DM status in both control and osteoporosis groups. The usefulness of serum sclerostin as a marker of osteoporosis marker among male elderly subjects was analyzed using a receiver operating characteristic (ROC) curve. The area under the curve (AUC) indicates the probability to predict an event. AUC values $>0.75$ indicate a good predictive performances. The association of sclerostin levels with BMD was assessed using Chi-square test, any $p<0.05$ was considered statistically significant while multivariate analysis was performed by logistic regression test.

\section{Results}

The subject characteristic is shown in Table 1 below. The whole sample was divided in two groups, according to the presence of osteoporosis (each group $\mathrm{n}=27$ ). The average age of osteoporosis group were $69.81 \pm 6.5$ years old, and non-osteoporosis group were $69.41 \pm 5.97$ years old. BMI was slightly lower in osteoporosis group $60.74 \pm 8.02 \mathrm{~kg} / \mathrm{m} 2$ for compare to non-osteoporosis group $69.59 \pm 14.16 \mathrm{~kg} / \mathrm{m} 2$. Most of samples in both groups didn't smoke and didn't drink any alcohol. Both osteoporosis and non osteoporosis mostly have good sun exposure $(70.4 \%$ vs $66.7 \%)$.

Table 1: Subject characteristic $(n=54)$

\begin{tabular}{|c|c|c|c|}
\hline Variables & $\begin{array}{l}\text { Non-osteoporosis } \\
(\mathrm{n}=\mathbf{2 7})\end{array}$ & $\begin{array}{l}\text { Osteoporosis } \\
(n=27)\end{array}$ & $p$ value \\
\hline Age, (years), Mean \pm SD & $69.41 \pm 5.97$ & $69.81 \pm 6.5$ & 0.812 \\
\hline Weight, $(\mathrm{kg})$, Mean $\pm \mathrm{SD}$ & $69.59 \pm 14.16$ & $60,74 \pm 8.02$ & 0.007 \\
\hline Height, $(\mathrm{cm})$, Mean \pm SD & $167.44 \pm 6.807$ & $166.44 \pm 5.63$ & 0.559 \\
\hline Bone mass index, $\left(\mathrm{kg} / \mathrm{m}^{2}\right)$, Mean $\pm \mathrm{SD}$ & $24.68 \pm 4.14$ & $21,92 \pm 2.96$ & 0.005 \\
\hline \multicolumn{4}{|l|}{ Education level, n (\%) } \\
\hline Never enrolled & $0(0 \%)$ & $2(7.4 \%)$ & \\
\hline Elementary school & $4(14.8 \%)$ & $4(14.8 \%)$ & \\
\hline Junior high school & $2(7.4 \%)$ & $3(11.1 \%)$ & \\
\hline High school & $7(25.9 \%)$ & $9(33.3 \%)$ & \\
\hline Diplomas & $4(14.8 \%)$ & $1(3.7 \%)$ & \\
\hline Bachelors & $10(37 \%)$ & $8(29.6 \%)$ & \\
\hline \multicolumn{4}{|l|}{ Smoking status, n (\%) } \\
\hline Yes & $6(22.2 \%)$ & $5(18.5 \%)$ & 0.735 \\
\hline Mo & $21(77.8 \%)$ & $22(81.5 \%)$ & \\
\hline \multicolumn{4}{|l|}{ Smoking intensity, n (\%) } \\
\hline Mild & $2(33.3 \%)$ & $3(60.0 \%)$ & 0.649 \\
\hline Moderate & $3(50 \%)$ & $1(20.0 \%)$ & \\
\hline Severe & $1(16.7 \%)$ & $1(20.0 \%)$ & \\
\hline \multicolumn{4}{|l|}{ Alcohol, n (\%) } \\
\hline Yes & $0(0.0 \%)$ & $1(3.7 \%)$ & 1.000 \\
\hline \multirow{2}{*}{\multicolumn{4}{|c|}{ Sun exposure, $n(\%)$}} \\
\hline & & & \\
\hline Good & $19(70.4 \%)$ & $18(66.7 \%)$ & 0.770 \\
\hline \multirow{2}{*}{\multicolumn{4}{|c|}{ Activity level, n (\%) }} \\
\hline & & & \\
\hline Active & $18(66.7 \%)$ & $18(66.7 \%)$ & 1.000 \\
\hline Not active & $9(33.3 \%)$ & $9(33.3 \%)$ & \\
\hline \multicolumn{4}{|l|}{ Diabetes mellitus, $n$ (\%) } \\
\hline Yes & $3(11.1 \%)$ & $3(11.1 \%)$ & 1.000 \\
\hline No & $24(88.9 \%)$ & $24(88.9 \%)$ & \\
\hline
\end{tabular}

\section{Association between sclerostin serum level and osteoporosis in male elderly}

ROC curve analysis was done generating cutoff values for serum sclerostin of $302.5 \mathrm{pg} / \mathrm{mL}$ as osteoporosis risk factor in elderly male subjects $(A \cup C=0.724 ; p=0.005)$. Based on such cutoff values, the diagnostic performance of serum sclerostin as a potential biomarker of osteoporosis in male elderly subjects revealed a sensitivity of $59.3 \%$ and a specificity of $81.5 \%$ (Figure 1).

The subject characteristic is shown in table 1 below. The whole sample was divided in two groups, according to the presence of osteoporosis (each group $\mathrm{n}=27$ ). The average age of osteoporosis group were 69.816 .5 years old, and non-osteoporosis group 


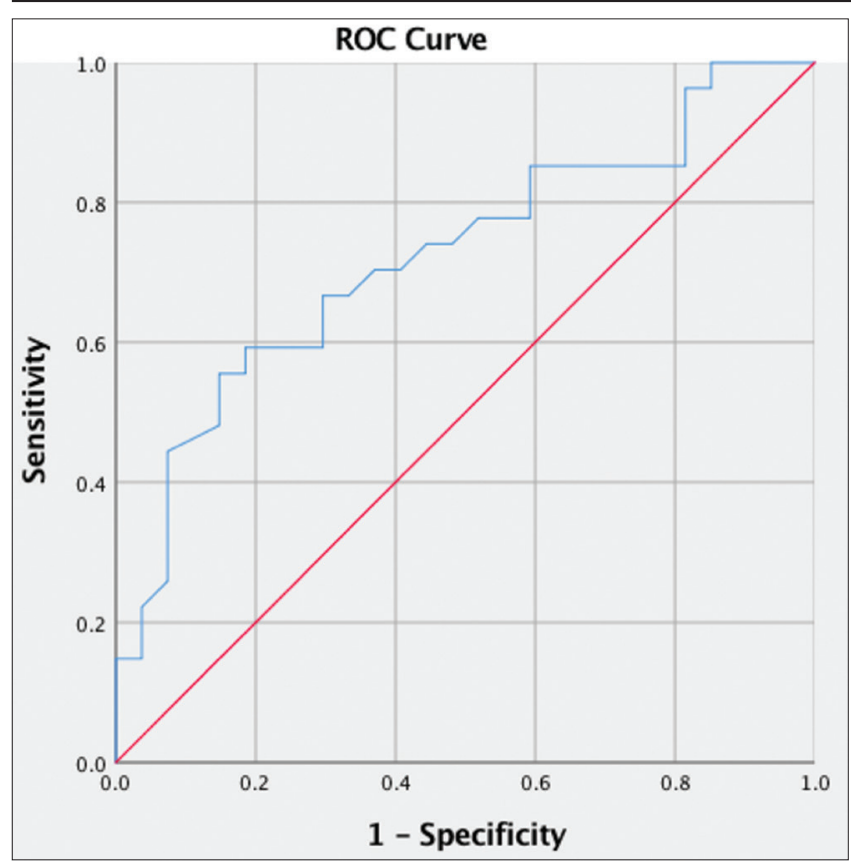

Figure 1: Receiver operating characteristic curve analysis of serum sclerostin as marker for osteoporosis risk factor in male elderly subjects

were 69.415 .97 years old. BMI was slightly lower in osteoporosis group $60.748 .02 \mathrm{~kg} / \mathrm{m} 2$ for compare to non-osteoporosis group $69.5914 .16 \mathrm{~kg} / \mathrm{m} 2$. Most of samples in both groups didnt smoke and didnt drink any alcohol. Both osteoporosis and non osteoporosis mostly have good sun exposure ( $70.4 \%$ vs $66.7 \%)$.

Results of the association analyses between sclerostin and osteoporosis in male elderly subjects are shown in Table 2. High circulating sclerostin level $(\geq 302.5 \mathrm{pg} / \mathrm{mL})$ was significantly associated with osteoporosis in male elderly subjects (odds ratio $[\mathrm{OR}]=6.4, \mathrm{p}=0.0020,95 \% \mathrm{Cl}: 1.856-22.068)$.

\section{Association between confounding variables and osteoporosis in male elderly subject}

Result of multivariate analysis using logistic regression showed that sclerostin remained the only independent risk factor for osteoporosis in male elderly subjects rather than age, BMI, smoking status, alcohol, physical activity, sun exposure, and DM, as shown in Table 3.

Table 2: Association between serum sclerostin and osteoporosis

Level of sclerostin Osteoporosis Non-osteoporosis Odds ratio $(95 \% \mathrm{Cl}) \quad \mathrm{p}$ value $(\mathrm{pg} / \mathrm{mL})$

\begin{tabular}{lllll}
\hline Sclerostin $\geq 302.5 \mathrm{pg} / \mathrm{mL}$ & $16(59.3 \%)$ & $5(18.5 \%)$ & $6.4(1.856-22.068)$ & 0.0020
\end{tabular} Sclerostin $<302.5 \mathrm{pg} / \mathrm{mL} \quad 11(40.7 \%)$

\section{Discussion}

Total subjects in this study were 54 elderly men aged more than 60 years. The mean age for all subjects was $69.61 \pm 6.91$ years. Theoretically, at this age, the risk for osteoporosis in men is increasing. Bone mass loss in men begins at the age of 40 years but occurring in slower rate compared to women, but the fragility becomes more significant when men turn 50 years of age. Starting at the early 50 s as many as one in eight men will develop osteoporosis [4]. This study also found that the mean age in the group with osteoporosis was slightly higher than the group without osteoporosis, $69.81 \pm 6.5$ years versus $69.41 \pm 5.97$ years, where the risk of osteoporosis generally increases with age.

Table 3: Logistic regression analysis with osteoporosis as a dependent variable

\begin{tabular}{llll}
\hline Variable & Exp (B) & Cl 95\% & p values \\
\hline Age & 1.854 & $0.350-9.817$ & 0.468 \\
Bone mass index & 2.159 & $0.377-12.347$ & 0.387 \\
Smoking status & 0.356 & $0.056-2.822$ & 0.356 \\
Alcohol & 3.642 & 0.000 & 1.000 \\
Physical activity & 0.833 & $0.185-3.753$ & 0.812 \\
Sun exposure & 0.529 & $0.113-2.477$ & 0.419 \\
Diabetes mellitus & 0.545 & $0.63-4.705$ & 0.581 \\
Sclerostin level & 15.906 & $3.126-80.993$ & $0.001^{\text {* }}$ \\
\hline
\end{tabular}

Most of the subjects in this study were still working actively, and some who did not work and retired said that they were still doing good daily physical activities. Based on characteristic of subject, 25 people $(46.3 \%)$ said that they had retired and stopped working but were still active in their activities at home and in their social environment, while the rest were mostly entrepreneurs 23 people $(42.6 \%)$, civil servants 3 people $(5.6 \%)$, labor 1 person (1.9\%), and other 1 person (1.9\%). Several studies have investigated that the presence of thickened BMD on the femoral neck was significantly higher in people who work mostly standing. Other studies suggest that BMD will increase if a person has a job with strenuous activities ever since he was young. However, some other studies have shown no relationship between occupational exposure and BMD [5].

A total of 3 people $(11.1 \%)$ from each group both osteoporosis and non-osteoporosis have suffered from type II DM while the remaining 48 people have suffered from hypertension $(11.1 \%)$, heart $(5.6 \%)$, gout $(5.6 \%)$, osteoarthritis (3.7\%), and others (18.5\%). DM type II was associated with higher incidence of fractures in elderly male patients, but not associated with osteoporosis or low BMD. Higher incidence of fracture among diabetes patients was because of falls due to internal and external complications such as hypoglycemia, which is frequent in geriatrics, poor vision due to $D M$ retinopathy or cataracts, episodes of nocturia due to uncontrolled DM, poor balance due to diabetic foot, neuropathy, orthostatic hypotension, and poor joint mobility due to DM arthropathy [6].

Our study found no significant difference between sun exposure and osteoporosis in the two groups $p=0.770$ $(p>0.05)$ and our results with consistent with research by Raveendran et al. Sunlight is such great source of Vitamin D, which is thought to affect bone health [7]. To date, there are not many studies regarding sun exposure and osteoporosis. One study conducted by ChanYang et al. (2021) in Korea involving 419.934 samples 
without osteoporosis compared to 94.932 samples with osteoporosis aged $\geq 60$ years studied that the duration of sunlight to cause osteoporosis was about 7 years. They found that the prevalence of osteoporosis was lower in patients who received adequate sunlight than controls, $50.3 \%$ (9.726/19.351) versus 51.5\% (19.930/38.702), $p=0.005$. The main source of Vitamin $D$ in humans is synthesized when the skin is exposed to sunlight. When a person is exposed to sunlight for $24 \mathrm{~h}, 10,000-20,000 \mathrm{IU}$ of Vitamin $D$ will be formed. Several factors will affect the production of Vitamin $D$ in the skin such as high skin pigmentation in African population and aging so that in the elderly, sun exposure may not be associated with the incidence of osteoporosis because the levels of Vitamin $D$ needed are not adequate. Several factors could influence the level of Vitamin D such as sun exposure, other comorbidites that affect bone and most importantly calcium intake. Current recommendations and daily intakes of vitamin D is at least $1200 \mathrm{mg}$ daily [8].

Circulating sclerostin levels were higher in the osteoporosis group than non-osteoporosis group, which is $336.15 \pm 110.65 \mathrm{pg} / \mathrm{mL}$ compared to $257.89 \pm 64.06 \mathrm{pg} / \mathrm{mL}$ with a minimum value of $159.9 \mathrm{pg} / \mathrm{mL}$ and a maximum $680.70 \mathrm{pg} / \mathrm{mL}$. To date, there has been no cutoff value for sclerostin yet. Study conducted by Pal et al. (2013) about osteoporosis in men suggests that sclerostin levels will increase with age. They measured the level of sclerostin in older men compared to young adults and found that it was $70.4 \pm 17$ versus $63.9 \pm 11.5$ $\mathrm{pmol} / \mathrm{L} ; \mathrm{p}=0.019$, respectively, with a conversion factor of $1 \mathrm{pmol} / \mathrm{l}=22.5 \mathrm{pg} / \mathrm{mL}$ which is around $1584 \mathrm{pg} / \mathrm{mL}$ versus $1437 \mathrm{pg} / \mathrm{mL}$ [9]. Another study also found in higher sclerostin levels postmenopausal compared to women before menopause where the average serum sclerostin level was $338.56 \pm 98.33 \mathrm{pg} / \mathrm{mL}$ in women before menopause compared to $458.10 \pm 42.64 \mathrm{pg} / \mathrm{mL}$ in the postmenopausal group of women [10].

We found that serum sclerostin levels were significantly higher in male elderly with osteoporosis compared with male elderly without osteoporosis. This result was consistent with Register et al., where sclerostin was found to be independently associated with BMD and subclinical cardiovascular event (atherosclerosis calcification plaque) without being influenced by sex, BMI, or HbA1C level. The relationship between serum sclerostin levels and BMD was also studied by Ishimura et al. (2014) where this study was conducted on patients undergoing hemodialysis to detect CKD-MBD. Serum sclerostin levels were found to be higher in patients with Stage 5 CKD than in those without CKD. Their study also found a correlation between serum sclerostin levels and radius BMD, approximately at $1 / 3$ distal radius and ultradistal radius with $r=0.454$ and $r=0.329$, respectively $(p<0.001)$. After multivariate analysis, serum sclerostin also remained correlated with $B M D$ in $1 / 3$ distal radius and ultradistal radius with $\mathrm{R}^{2}$ which were 0.629 and 0.465 , respectively, and $p<0.001$, where other controlled variables were age, duration of hemodialysis, sex, history of diabetes, BMI, and intact PTH levels. Another study conducted by Modder et al. (2011) who found that serum sclerostin levels were not associated with bone density and microstructure in both men and women in young adults but significantly correlated with elderly men and women. Their study found a correlation between sclerostin and total body BMD and BMD in women over 60 years of age was $r=0.49$ and $0.46(p<0.001)$ while in men over 60 years was $r=0.5$ and $0.44(p<0.001)$ [11].

Phase III experimental studies in humans using human monoclonal antibodies that act to inhibit the action of sclerostin showed the efficacy of anti-sclerostin to reduce fracture risk in elderly postmenopausal women compared to placebo. The Fracture Study in Postmenopausal Women with Osteoporosis (FRAME) evaluated the administration of human monoclonal antibody anti-sclerostin at a dose of $210 \mathrm{mg}$ per month for 12 months compared with placebo in 6390 patients with postmenopausal osteoporosis. The BMD improvement in the lumbar spine was $13.3 \%$ higher compare to placebo group, in the femoral neck and hip area, the BMD rate increased $5.9-6.9 \%$ higher compare to placebo group. The effect on fracture risk was also consistent with the anti-sclerostin effect on BMD where after 12 months of administration, the risk of vertebral fracture decreased by $73 \%$ (incidence of fracture was $0.5 \%$ in the treatment group and $1.8 \%$ in the placebo). This study found a total of 20 incidents of new fractures, where three patients were in the treatment group and the remaining 17 were from the placebo group [12].

The effect of human monoclonal antibodies that inhibit the action of sclerostin which indicate anti-sclerostin efficacy was also evaluated in men in a BRIDGE Phase III study using a total of 246 elderly men aged 55-90 years who have lumbar T-score, total femur or femoral neck $\leq-2.5 \mathrm{SD}$ or $\leq-1.5 \mathrm{SD}$ with a history of fracture. The increase in BMD in the lumbar spine and total femur was higher in the treatment group than in the placebo after 12 months of intervention ( $12.1 \%$ vs. $1.2 \%$ and $2.5 \%$ vs. $-0.5 \%$, with $p<0.001)$, however, data regarding fracture incidence were not investigated in this study [13].

The relationship between high sclerostin levels and the increased risk of osteoporosis in elderly men is probably due to sclerostin action by inhibiting bone formation. Sclerostin plays an important role in inhibit osteoblasts proliferation and differentiation in both early and late phases. Sclerostin also stimulates osteoblast apoptosis and RANKL secretion from osteocytes which induce osteoclast genesis, leading to an increase in bone resorption. The Wnt/ $\beta$-catenin signaling pathway plays an important role in regulating cell proliferation and differentiation, including osteoblasts and its differentiation from mesenchymal stem cells. Wnt/ $\beta$-catenin signaling pathway is also tightly regulated by several types of secreted antagonists, such as sclerostin and Dickkopfrelated protein 1 (DKK1). Similar to the role of sclerostin in bone regulation, DKK1 also negatively regulates bone formation. Sclerostin and DKK1 inhibit the Wnt/ $\beta$-catenin signaling pathway through binding to LRP5/6, displacing the Wnt proteins, leading to the dissociation of the LRP5/6 and 
Frizzled receptor complex. This results in phosphorylation of $\beta$-catenin and eventually degraded by proteasome. High circulating sclerostin level will inhibit Wnt/ $\beta$-catenin signaling pathway, thus inhibit osteoblast and increase osteoclast activity. This mechanism will lead to further condition we known as osteoporosis and explained why high circulating sclerostin was one of risk factors of developing osteoporosis among elderly male subject in the future [2].

Multivariate analysis found that only sclerostin was shown to be associated with incidence of osteoporosis in the male elderly population (OR 15.906; CI 3.126-80.993; $p=0.001$ ). To date, there are still few studies examining sclerostin, especially in the male elderly population but there is a study conducted by Daniel Cejka et al. (2012) in which sclerostin correlates with BMD independently after removing confounding variables. This study was conducted among Stage 5 CKD patients who underwent regular hemodialysis and found that sclerostin was significantly correlated with BMD in the femoral neck, lumbar spine, and radius with $p=0.04,0.006$, and 0.04 , respectively [14]. Study from Lapauw et al. after adjusting the variables for age, weight, and height, found that sclerostin was positively correlated with BMI in the male geriatric population both in the cortex, trabecular, and tibia $(p<0.001)$ [15].

The limitation of this study was data taken at 1 time, so it is difficult to determine the progression of sclerostin levels from before osteoporosis and after osteoporosis. Ideally, this study should be conducted prospectively both in vivo and in vitro so that the effect of sclerostin levels on the incidence of osteoporosis in men is more pronounced. Moreover, there are several markers and conditions that affect osteoporosis that should be studied further, such as testosterone level and burn turnover markers that were not measured in this study. Several variables such as physical activity have not been studied yet regarding its intensity, duration, and more specific types so that their effect on BMD can be clarified.

\section{Conclusions}

High circulating serum sclerostin level (cutoff $\geq 302.5 \mathrm{pg} / \mathrm{mL}$ ) is a risk factor for osteoporosis in elderly men.

\section{References}

1. World Health Organization. Indonesia: Life Expectancy. Geneva: World Health Organization; 2017.

2. Moester MJ, Papapoulos SE, Löwik CW, van Bezooijen RL. Sclerostin: Current knowledge and future perspectives. Calcif Tissue Int. 2010;87:99-107. https://doi.org/10.1007/ s00223-010-9372-1

\section{PMid:20473488}

3. Yavropoulou M, Xygonakis C, Lolou M, Karadimou F, Yovos J. The sclerostin story: From human genetics to the development of novel anabolic treatment for osteoporosis. Hormones (Athens). 2014;13(4):323-37. https://doi.org/10.14310/horm.2002.1552 PMid:25555179

4. D'Amelio P, Isaia GC. Male osteoporosis in the elderly. Int J Endocrinol. 2015;2015:907689.

PMid:26457082

5. Brahm $H$, Mallmin $H$, Michaëlsson $K$, Ström $H$, Ljunghall $S$. Relationships between bone mass measurements and lifetime physical activity in a Swedish population. Calcified Tissue Int. 1998;62(5):400-12. https://doi.org/10.1007/s002239900452 PMid:9541517

6. Jackuliak P, Payer J. Osteoporosis, fractures, and diabetes. Int J Endocrinol. 2014;2014:820615.

PMid:25050121

7. Raveendran A, Raveendran A, Khandelwal N, Sen RK, Thakur JS, Dhaliwal LK, et al. Prevalence and related risk factors of osteoporosis in peri- and postmenopausal Indian women. J Midlife Health. 2011;2(2):81-7. https://doi. org/10.4103/0976-7800.92537

PMid:22408337

8. Damaso Ê, de Paula FJ, Franceschini SA, Vieira CS, Ferriani RA, de Sá MF, et al. Does the access to sun exposure ensure adequate levels of 25-hydroxyvitamin D? Rev Bras Ginecol Obstet. 2017;39(3):102-9. https://doi.org/10.1055/s-0037-1600520 PMid:28297731

9. Bhattoa HP, Wamwaki J, Kalina E, Foldesi R, Balogh A, AntalSzalmas P. Serum sclerostin levels in healthy men over 50 years of age. J Bone Miner Metab. 2013;31(5):579-84. https://doi. org/10.1007/s00774-013-0451-z PMid:23525828

10. Zou J, Li X, Yang F. Association between sclerostin, serum bone turnover markers and bone density in postmenopausal women with fragility fracture. Int J Clin Exp Med. 2016;9(7):12984-91. https://doi.org/10.1002/jbmr.217

11. Mödder UI, Hoey KA, Amin S, McCready LK, Achenbach SJ Riggs $\mathrm{BL}$, et al. Relation of age, gender, and bone mass to circulating sclerostin levels in women and men. J Bone Miner Res. 2011;26(2):373-9.

PMid:20721932

12. Cosman F, Crittenden DB, Adachi JD, Binkley N, Czerwinski E, Ferrari S, et al. Romosozumab treatment in postmenopausal women with osteoporosis. N Engl J Med. 2016;375(16):1532-43. https://doi.org/10.1056/nejmoa1607948 PMid:27641143

13. Lewiecki EM, Blicharski T, Goemaere S, Lippuner $\mathrm{K}$, Meisner PD, Miller PD, et al. A phase III randomized placebo-controlled trial to evaluate efficacy and safety of romosozumab in men with osteoporosis. J Clin Endocrinol Metab. 2018;103(9):3183-93. https://doi.org/10.1210/ jc.2017-02163 PMid:29931216

14. Kuo TH, Lin WH, Chao JY, Wu AB, Tseng CC, Chang YT, et al. Serum sclerostin levels are positively related to bone mineral density in peritoneal dialysis patients: A cross-sectional study. BMC Nephrol. 2019;20(1):266-74. https://doi.org/10.1186/ s12882-019-1452-5

PMid:31315601

15. Lapauw B, Vandewalle S, Taes Y, Goemaere S, Zmierczak H, Collette J. Serum sclerostin levels in men with idiopathic osteoporosis. Eur J Endocrinol. 2013;168(4):615-20. https://doi. org/10.1530/eje-12-1074

PMid:23389587 